\title{
Inhomogeneous forcing and transient climate sensitivity
}

\author{
Drew T. Shindell
}

Understanding climate sensitivity is critical to projecting climate change in response to a given forcing scenario. Recent analyses ${ }^{1-3}$ have suggested that transient climate sensitivity is at the low end of the present model range taking into account the reduced warming rates during the past 10-15 years during which forcing has increased markedly ${ }^{4}$. In contrast, comparisons of modelled feedback processes with observations indicate that the most realistic models have higher sensitivities ${ }^{5,6}$. Here I analyse results from recent climate modelling intercomparison projects to demonstrate that transient climate sensitivity to historical aerosols and ozone is substantially greater than the transient climate sensitivity to $\mathrm{CO}_{2}$. This enhanced sensitivity is primarily caused by more of the forcing being located at Northern Hemisphere middle to high latitudes where it triggers more rapid land responses and stronger feedbacks. I find that accounting for this enhancement largely reconciles the two sets of results, and I conclude that the lowest end of the range of transient climate response to $\mathrm{CO}_{2}$ in present models and assessments $\left(<1.3^{\circ} \mathrm{C}\right)$ is very unlikely.

Modelled transient climate responses were in good agreement with the understanding of historical forcing and observed warming trends in most analyses to 2006 (ref. 8). Recent measurements posed a problem, however: warming rates were slower during the past 10-15 years while positive forcing continued to increase rapidly and new observations led to reduced estimates of offsetting negative aerosol forcing ${ }^{4,9}$. Although there are uncertainties in the recent forcing trends and at least part of the reduced warming rate could be due to internal variability, analyses in both the scientific literature ${ }^{1,2}$ and the popular press ${ }^{3}$ accounting for those factors concluded that climate sensitivity is likely towards the low end of present models' range.

Inferring climate sensitivity from recent observations requires a thorough understanding of both recent forcing and the global mean response to various forcing agents. Although the forcing has been studied in detail, the global mean response has conventionally been assumed to be the same for all forcing agents (in all such analyses, not only the most recent). I examine the response to historical anthropogenic inhomogeneous forcing in the most recent set of state of the art climate model simulations: the Coupled Model Intercomparison Project Phase 5 (CMIP5; ref. 10). Simulations to examine the influence of aerosols and ozone on climate were part of CMIP5 (ref. 10), but were relegated to a low priority and few results are available. Hence to examine the response to aerosols and ozone, I analyse CMIP5 historical simulations of the response to all forcings (histAll), to well-mixed greenhouse gas (WMGHG) forcing (histGHG) and to natural forcing (histNat), using the residual of histAll - (histGHG + histNat) following two methods. Method 1 assumes that stratospheric water vapour forcing induces a response similar to WMGHGs, so that the residual (with scaled histGHG) represents the response to aerosol + ozone + land-use (LU; representing anthropogenic changes in vegetation cover and land usage). Method 2 assumes that the response to positive stratospheric water vapour forcing offsets the response to negative LU forcing, leaving a residual representing only aerosols + ozone (Methods).

I include the eight models for which forcing due to aerosols and ozone has been documented ${ }^{11}$ and all of these transient historical climate simulations are available. I evaluate the transient climate response (TCR), defined as the global mean temperature change in response to gradually increasing $\left(1 \% \mathrm{yr}^{-1}\right) \mathrm{CO}_{2}$ at the time of its doubling in a given model ${ }^{12}$ (all values annual averages). For consistency, the response to other forcings, which I refer to more generally as transient climate sensitivity, is given using the same scale (that is, the response per unit forcing times a model's doubled $\mathrm{CO}_{2}$ forcing). Uncertainty in the TCR for a particular model stems from both the responses and the forcings, with the poorly documented LU forcing contributing the largest fraction in these calculations.

All of the available CMIP5 models show greater TCR for historical inhomogeneous forcing than for WMGHG forcing (Fig. 1 and Supplementary Table 1). The TCR for WMGHG is $2.0 \pm 0.3^{\circ} \mathrm{C}$ (mean and s.d. across model ensembles), whereas it is $2.9 \pm 1.0^{\circ} \mathrm{C}$ for aerosol + ozone + LU (Method 1) and 3.0 $\pm 1.1^{\circ} \mathrm{C}$ for aerosol + ozone (Method 2). Thus, the results are robust to the methodology for treating these minor forcing agents (LU and stratospheric water vapour), and seem to be dominated by the response to aerosol and ozone forcing. The TCR for aerosol + ozone is $45 \pm 38 \%$ (mean of Methods 1 and 2; Supplementary Table 1) greater than the TCR calculated from historical WMGHG simulations (histGHG). In comparison with independent TCR estimates from these same models from the response to $1 \%$ per year $\mathrm{CO}_{2}$ increases ${ }^{13}$, which are $2.0 \pm 0.3{ }^{\circ} \mathrm{C}$, the aerosol + ozone TCR is $53 \pm 46 \%$ greater.

Analysis of the large-scale forcing and temperature response patterns provides both further confidence that the enhanced TCR is due to aerosol + ozone forcing and insight into the large spread in model results. The models have greater net negative inhomogeneous forcing in the Northern Hemisphere (NH) than in the Southern Hemisphere $(\mathrm{SH})$ by $-0.97 \pm 0.57 \mathrm{~W} \mathrm{~m}^{-2}$, and in the $\mathrm{NH}$ extratropics (NHext; $28^{\circ}-90^{\circ}$ ) than in the SHext by $-1.07 \pm 0.66 \mathrm{~W} \mathrm{~m}^{-2}$ (Supplementary Table 3). The extratropical asymmetry results from a very strong asymmetry in aerosol forcing $\left(-1.32 \pm 0.57 \mathrm{~W} \mathrm{~m}^{-2}\right)$ that is partially offset by more positive ozone forcing in the NHext than the SHext $\left(0.40 \pm 0.11 \mathrm{~W} \mathrm{~m}^{-2}\right.$; Supplementary Table 2).

It has been shown previously that forcing in the $\mathrm{NH}$ extratropics causes a greater global mean temperature response than forcing in the tropics ${ }^{14-18}$. In particular, NHext forcing caused $\sim 50 \%$ greater 

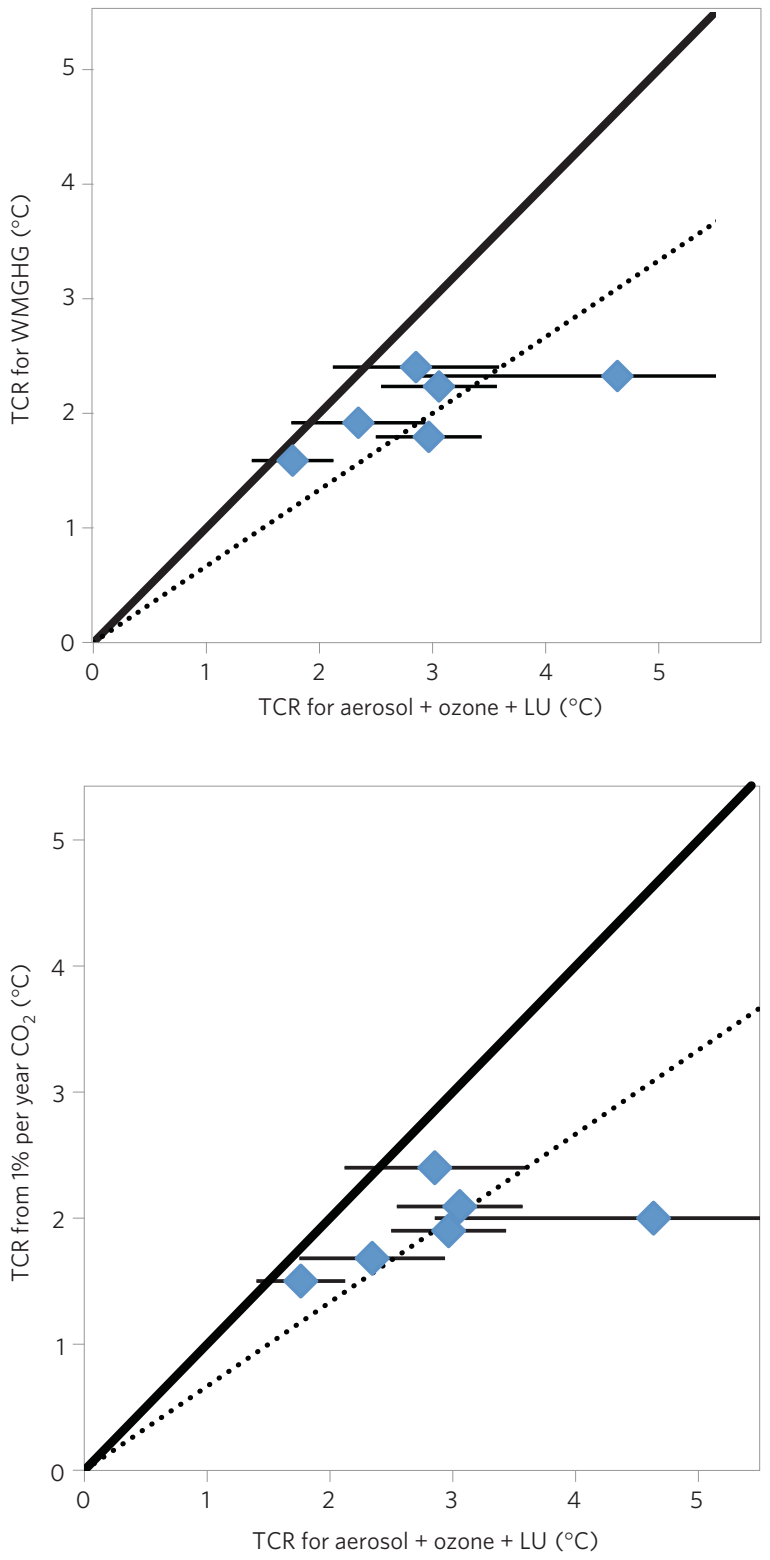

Figure 1 | Comparison of transient climate response for well-mixed greenhouse gas forcing and for aerosol + ozone + land-use forcing. Response to well-mixed greenhouse gas (WMGHG) is based on the histGHG simulations (top) or $1 \%$ per year $\mathrm{CO}_{2}$ simulations (bottom), whereas the response to aerosol + ozone + land-use (LU) is based on histAll - (histGHG+histNat) (using Method 1). The solid line shows 1:1 correspondence, whereas the dashed line shows $50 \%$ greater transient climate response (TCR) for aerosol + ozone + LU. Uncertainties are 95\% confidence intervals incorporating uncertainties in forcing and modelled temperature change. Uncertainties in TCR for WMGHG are comparable to the symbol size ( $\sim 12 \%)$. Some overlapping points have been very slightly displaced for clarity.

equilibrium response than equivalent global mean tropical forcing in the GISS-E climate model for aerosols (or even for idealized $\mathrm{CO}_{2}$ perturbations), and forcing in the $\mathrm{NH}$ caused $\sim 18 \%$ greater response than forcing in the SH (ref. 16). In the ECHAM4 model, tropospheric ozone forcing in the NHext caused a $20-61 \%$ greater global mean surface temperature response than equivalent globally homogeneous forcing ${ }^{18}$. Thus, it seems entirely logical that, because aerosol + ozone forcing is preferentially in the NHext, this forcing will cause a greater global mean transient response.

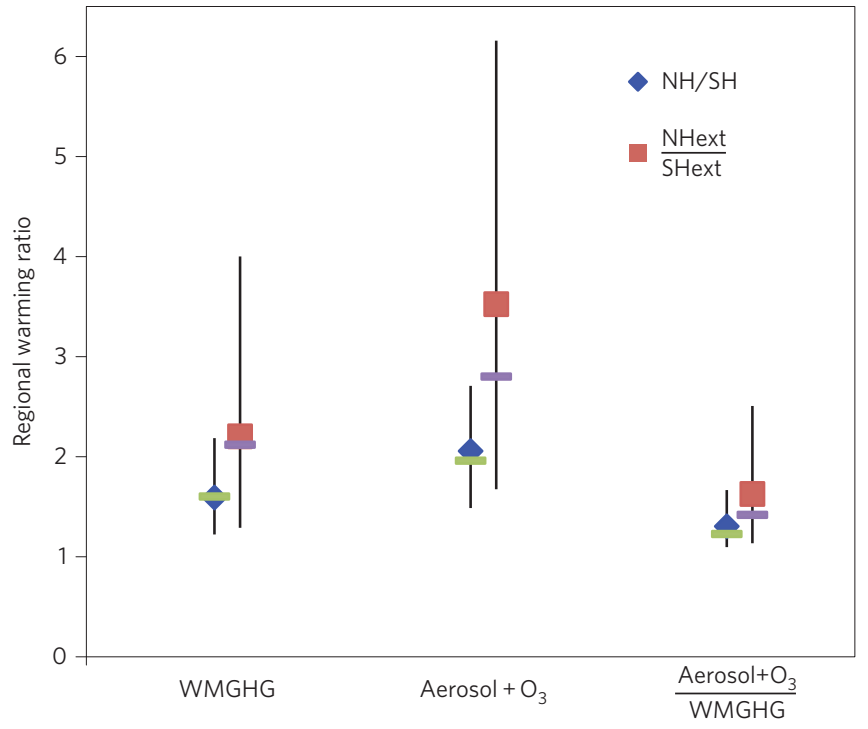

Figure 2 | Ratios of regional temperature responses to well-mixed greenhouse gas and inhomogeneous forcings in CMIP5 simulations. Aerosol + ozone $\left(\mathrm{O}_{3}\right)$ results are based directly on histAll - (histGHG + histNat; that is, Method 2). Diamonds and squares are mean values, horizontal lines are medians, and the ranges across the models are shown as vertical lines.

That the aerosol + ozone forcing drives greater trends in the $\mathrm{NH}$ than in the $\mathrm{SH}$ is clear in analysis of the temperature response in these CMIP5 models (Fig. 2). All of the models have an enhanced transient response in the $\mathrm{NH}$ relative to the $\mathrm{SH}$ for increasing WMGHG, and the mean model response in the NHext is more than double the SHext response to WMGHG. This is attributable to the greater land area in the $\mathrm{NH}$ and NHext, which responds more rapidly to forcing, and the greater area with strong snow and ice albedo feedbacks ${ }^{16,18,19}$. In response to aerosol + ozone forcing, the ratio of $\mathrm{NH} / \mathrm{SH}$ temperature response is $\sim 30 \%$ greater than the ratio for WMGHG forcing, however. The ratio of NHext to SHext temperature responses to aerosol + ozone forcing is $\sim 65 \%$ greater. In the few models that performed ensembles of historical response to aerosols alone (GFDL, GISS, CanESM and CSIRO; see Supplementary Information), the simulations show comparable but even larger enhancements of $44 \%$ and $94 \%$, respectively. Although there is a substantial range in these ratios across models, part of the North-versus-South difference is systematic across the forcing agents, and hence comparing the regional response ratios shows that these ratios are larger for aerosol + ozone forcing than for WMGHG forcing for all models (Fig. 2). Thus, the asymmetric distribution of forcing plays a significant role in causing different temperature responses in the two hemispheres and two extratropical zones, with an impact roughly one-third to two-thirds the magnitude of the effect of the uneven distribution of underlying transient climate sensitivity.

The response to WMGHG indicates that the transient sensitivity of the $\mathrm{NH}$ is $\sim 60 \%$ greater than that of the SH (Fig. 2). Hence, if all of the aerosol + ozone forcing was in the $\mathrm{NH}$, and the response was relatively localized in latitude ${ }^{20}$, one would expect roughly $30 \%$ greater global mean temperature response than for uniform forcing. In these CMIP5 models, $77 \%$ of the net aerosol + ozone forcing is in the $\mathrm{NH}$, and $82 \%$ of the extratropical forcing is in the NHext, implying that indeed the spatial asymmetry can account for a substantial portion of the enhancement found here.

In addition, while WMGHG forcing has increased through the present, aerosol + ozone forcing levelled off during recent decades, allowing more time for the climate system to respond to the 
full historical aerosol + ozone forcing. I performed calculations using a global impulse-response function ${ }^{21}$ (see Supplementary Information) driven by the temporally evolving aerosol + ozone forcing ${ }^{4}$ and by forcing with the same maximum magnitude but following the temporal evolution of WMGHG forcing. The difference shows that the earlier peak in forcing enhances the sensitivity to historical aerosols + ozone by $\sim 10 \%$ relative to WMGHG (probably a lower limit as the response times for $\mathrm{NH}$ land would be faster than the global mean response times). Additional factors, such as the distinct vertical distributions of aerosols and ozone, may also contribute to a stronger response per unit forcing relative to WMGHG.

These results support the conclusion that the greater response to inhomogeneous forcing is primarily driven by the fact that this forcing is predominantly located in the NHext where it activates the same processes that cause the response to WMGHG to be especially large in this region. Whereas WMGHG forcing is quasi-uniform in all models, a portion of the spread in the TCR to inhomogeneous forcing comes from the varied forcing distributions themselves rather than spatial variations in the response to inhomogeneous forcing, which seems to be fairly robust at large scales in climate models ${ }^{20}$.

Measurements show global mean warming of $0.68 \pm 0.20^{\circ} \mathrm{C}$ for $\sim 2000$ (1990-2009) in comparison with an 1860-1879 reference period using the HadCRUT4 temperature data $\operatorname{set}^{22}$ and including an adjustment for sampling bias ${ }^{23}$ (see Supplementary Information). Previous evaluations of TCR using these temperature trends assumed equal global mean response to forcing from any agent ${ }^{1,2}$. TCR consistent with observed temperature changes ( $\left.d T_{\text {observed }}\right)$ including the enhanced response to aerosol and ozone forcing seen in the CMIP5 models analysed here can be calculated using:

$T C R=F_{2 \times \mathrm{CO} 2} \times\left(d T_{\text {observed }} /\left(F_{\mathrm{WMGHG}}+E *\left(F_{\text {aerosols }}+F_{\text {Ozone }}+F_{\mathrm{LU}}\right)\right)\right)$

where $E$ is the enhanced response given as the ratio of the responses to inhomogeneous and WMGHG forcings, $F$ stands for forcing $\left(F_{\mathrm{WMGHG}}\right.$ is $2.47 \pm 0.24 \mathrm{~W} \mathrm{~m}^{-2}$ and includes small forcings due to stratospheric water, solar and contrails; $F_{\text {aerosols }}+$ $F_{\text {Ozone }}+F_{\text {LU }}$ is $-0.64(+0.3 /-0.5) \mathrm{W} \mathrm{m}^{-2}$, based on the Atmospheric Chemistry and Climate Model Intercomparison Project (ACCMIP) analysis $^{11}$, with aerosols reduced from the ACCMIP mean of $-1.2 \mathrm{~W} \mathrm{~m}^{-2}$ by $0.3 \mathrm{~W} \mathrm{~m}^{-2}$ to match the IPCC AR5 best estimate of $-0.9 \mathrm{~W} \mathrm{~m}^{-2}$ based on models and studies constrained with satellite observations ${ }^{9}$, and as in a previous study ${ }^{2}$, and thus assigned a smaller positive uncertainty), and $3.7 \mathrm{~W} \mathrm{~m}^{-2}$ is the best estimate of doubled $\mathrm{CO}_{2}$ forcing ${ }^{7}$. When assuming uniform sensitivity to all forcing agents $(E=1.00)$, I find nearly the same TCR as in the earlier study ${ }^{2}\left(1.4^{\circ} \mathrm{C} ; 1.0-2.1^{\circ} \mathrm{C} 95 \%\right.$ confidence interval) when using these forcing estimates. TCR is $1.7^{\circ} \mathrm{C}\left(1.3-3.2{ }^{\circ} \mathrm{C}\right)$, however, when including the enhanced sensitivity to aerosol and ozone forcing relative to $1 \% \mathrm{yr}^{-1} \mathrm{CO}_{2}(E=1.53$; range $1.18-2.43)$ or $1.6^{\circ} \mathrm{C}\left(1.3-3.1^{\circ} \mathrm{C}\right)$ using the enhancement relative to histGHG ( $E=1.45$; range 1.12-2.09; see also Supplementary Information). These ranges are largely consistent with those found in CMIP5 models $\left(1.2-2.4{ }^{\circ} \mathrm{C}, 95 \%\right.$ confidence; $1.1-2.6^{\circ} \mathrm{C}$ full range) or assessed as likely in the IPCC AR5 $\left(1.0-2.5^{\circ} \mathrm{C}\right)^{7}$, but whereas the uniform sensitivity TCR range indicates very low probabilities at the higher end of these ranges, the TCR range when accounting for the enhanced sensitivity to aerosol + ozone indicates very low probability only at the lowest end.

As these results do not suggest any change to estimates of the TCR to WMGHG, and WMGHG dominate long-term forcing (at least as projected under the Representative Concentration Pathways ${ }^{24}$ (RCPs)), they have minimal effect on projections of long-term climate change. Using a simple impulse-response function ${ }^{21}$ to estimate historical and future climate change, global mean values

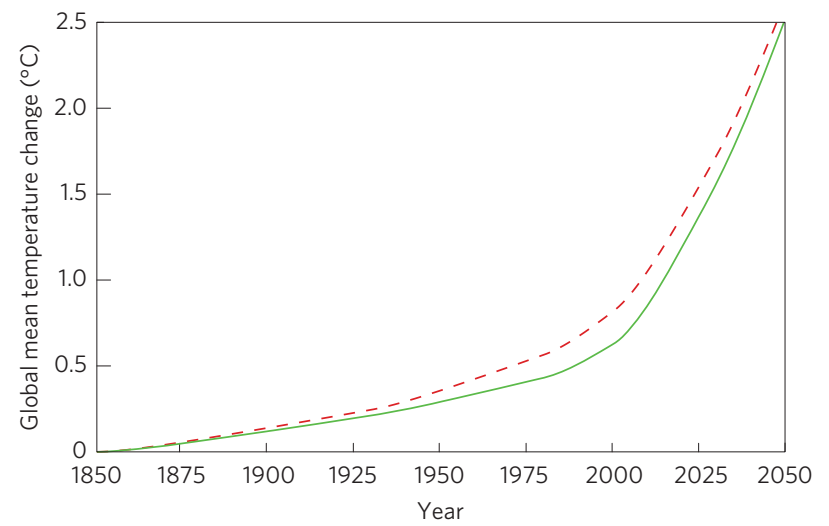

Figure 3 | Global mean temperature change estimates based on anthropogenic forcings obtained from a multi-model analysis ${ }^{11}$. The dashed line shows estimates assuming uniform sensitivity to all forcings, whereas the solid line shows results including the enhanced sensitivity to the inhomogeneous aerosol and ozone forcings ( $E=1.4$, accounting for the spatial distribution alone, as the contribution from the distinct temporal evolution is already included). Values are calculated with an impulse-response function ${ }^{21}$, with RCP8.5 used for the future projections, and include the reduced aerosol forcing used elsewhere in this study.

differ by less than $0.1^{\circ} \mathrm{C}$ after $\sim 2050$ whether the enhanced sensitivity to aerosol + ozone is accounted for or not (Fig. 3). However, there is $\sim 0.2^{\circ} \mathrm{C}$ less present warming accounting for the regional distribution of aerosol + ozone forcing, and more rapid warming during the coming decades when aerosols are projected to rapidly decrease in the RCPs.

These results have several additional implications. Forcing in CMIP5 models has been estimated assuming that all forcing agents have a similar forcing/response relationship as the one for WMGHG (ref. 13). Such an analysis would systematically overestimate net aerosol + ozone forcing (the dependence of this method on constant regional warming and feedback patterns has been noted ${ }^{25}$ ). Similarly, global mean temperature responses to projected aerosol and ozone forcing would be underestimated if the forcing distribution is not accounted for. Such biases affect simple box model calculations ${ }^{26}$, and lead to underestimates of aerosol impacts in calculations using simple model $\mathrm{s}^{27}$ relative to analogous calculations using full three-dimensional compositionclimate models ${ }^{28}$ (see also Supplementary Information).

As there is a high correlation between TCR and equilibrium climate sensitivity, the results suggest the lowest end of model equilibrium climate sensitivity estimates is also unlikely (consistent with palaeoclimate evidence ${ }^{29}$ ). Further work is clearly needed to better understand the large range in the apparent TCR in response to inhomogeneous forcing in present models (Fig. 1) and the large spread in the magnitude and distribution of the underlying aerosol forcing. However, given that analysis of observed temperature changes including the enhanced response to inhomogeneous forcing identified here and comparison of climate feedback processes in models against observational constraints ${ }^{5,6}$ both suggest that climate sensitivity is most likely towards the higher end of its nominal range, achieving climate protection goals will most likely require emissions reductions towards the high end of present estimates.

\section{Methods}

I examine all models for which both historical climate simulations and forcing diagnostics are available (see also Supplementary Information). I exclude NCAR-CAM3.5 and bcc-csm1-1 as they omit aerosol indirect effects. I also exclude GISS-E2-R as this model overestimates negative SH nitrate aerosol and ozone forcing ${ }^{11,30}$, so that its $\mathrm{NH}$ and $\mathrm{SH}$ forcings are quite similar, making its historical runs unsuited to studying the impact of hemispherically asymmetric 
forcing (other models have substantially greater hemispheric forcing gradients). Although they may be biased, historical aerosol-only simulations with that mode are included because there are only four available models and these results are used only in a single comparison complementing the primary analysis. This results in eight available models in the primary analysis (Supplementary Table 1).

The residual of histAll - (histGHG + histNat) includes not only the response to aerosols and ozone, but also to LU and stratospheric water, as well as any nonlinearities. The forcings are characterized as follows. Doubled $\mathrm{CO}_{2}$ forcing estimated using the fixed-sea surface temperature (SST) method in individual models is used when available ${ }^{12}$, with estimates derived by linear regression used in the few cases when fixed-SST simulations were not performed ${ }^{13}$. HistGHG forcing has been diagnosed from the CMIP5 simulations using linear regression ${ }^{13}$. I use these for all models except for CSIRO-Mk3-6-0, MRI-CGCM3 and HadGEM2, for which the regression-based analysis yielded values quite different from values using fixed-SSTs (which is used for aerosol forcing) in an earlier analysis ${ }^{12}$. For those models, fixed-SST results are used if available, and otherwis regression-method estimates are adjusted on the basis of the differences between the two methods (Supplementary Information). Ozone forcing is from ACCMIP analyses ${ }^{11}$, with the value for a few models that use prescribed ozone changes set to $0.27 \pm 0.14 \mathrm{~W} \mathrm{~m}^{-2}$, based on forcing calculations for those data sets (Supplementary Information), and using the multi-model mean spatial pattern. For LU, I take the central estimate of forcing as $-0.085 \mathrm{~W} \mathrm{~m}^{-2}$ with a range of the same magnitude so that $-0.17 \mathrm{~W} \mathrm{~m}^{-2}$ is the high-end forcing and the low-end forcing is zero (see Supplementary Information). The exception to this is the NorESM1-M model, which does not have LU forcing and hence a value of zero is used. For stratospheric water, I use a value of $0.07 \pm 0.05 \mathrm{~W} \mathrm{~m}^{-2}$ following the most recent assessment ${ }^{4}$. I then analyse the response to inhomogeneous forcing, histAll - (histGHG + histNat), in two ways: (Method 1) assuming the response to stratospheric water vapour is the same as that for WMGHG because it is similarly distributed globally (that is, the histGHG response is multiplied by $\left(F_{\mathrm{WMGHG}}+0.07\right) / F_{\mathrm{WMGHG}}$, where $F$ is forcing), and hence the residual represents aerosol + ozone $+\mathrm{LU}$, and (Method 2) assuming the LU and stratospheric water forcings offset one another, and hence the unmodified residual represents aerosol + ozone (see also Supplementary Information).

For this analysis, I compare simulated temperatures for 2000 (average over 1996-2005) with those during 1850-1859 (although for GFDL-CM3 I use 1860-1869 for the first period, the earliest available; and for HadGEM2 I used December 1859-November 1869 and December 1995-November 2005), with model drift removed by subtracting changes over the same time periods in control runs. Temperature averages are taken over up to five available ensemble members. Values are very similar to those I obtain with these decadal differences when instead using linear regression over the full length of the simulations ${ }^{13}$.

TCR for the models is simply given by the simulated temperature change divided by the imposed forcing, all multiplied by the doubled $\mathrm{CO}_{2}$ forcing (Supplementary Information). To calculate TCR from observations, using the equation given in the text, forcing from solar and contrails is taken as $0.1 \mathrm{~W} \mathrm{~m}^{-2}$ in total ${ }^{4}$. Uncertainties in TCR are computed with a Monte Carlo approach incorporating uncertainties in historical temperature change, forcing and response enhancement for inhomogeneous forcing (the value of $E$ ), all of which are assumed to be independent. Given that the TCR incorporating the enhanced response to inhomogeneous aerosol forcing is quite sensitive to the magnitude of that forcing, the results are in turn quite sensitive to the assumed reduction of the modelled aerosol forcing values. For example, if I do not include the $0.3 \mathrm{~W} \mathrm{~m}^{-2}$ bias-adjustment to the aerosol forcing, the mean TCR increases by $0.7^{\circ} \mathrm{C}$. As I used the smaller aerosol forcing value including this adjustment in the TCR calculation from observed surface temperature changes, I reduced the range of the positive uncertainty on the aerosol forcing, but further work is needed to better constrain aerosol forcing.

Received 2 October 2013; accepted 16 January 2014; published online 9 March 2014

\section{References}

1. Ring, M. J., Lindner, D., Cross, E. F. \& Schlesinger, M. E. Causes of the global warming observed since the 19th century. Atmos. Clim. Sci. 2, 401-415 (2012).

2. Otto, A. et al. Energy budget constraints on climate response. Nature Geosci. 6, 415-416 (2013).

3. The Economist, Climate Science: A Sensitive Matter (The Economist Group, 2012)

4. Myhre, G. et al. in Climate Change 2013: The Physical Science Basis (eds Stocker, T. F. et al.) Ch. 8 (IPCC, Cambridge Univ. Press, 2013).

5. Fasullo, J. \& Trenberth, K. A Less cloudy future: The role of subtropical subsidence in climate sensitivity. Science 338, 792-794 (2012).
6. Sherwood, S. C., Bony, S. \& Dufresne, J-L. Spread in model climate sensitivity traced to atmospheric convective mixing. Nature 505, 37-42 (2014).

7. Collins, M. et al. in Climate Change 2013: The Physical Science Basis (eds Stocker, T. F. et al.) Ch. 12 (IPCC, Cambridge Univ. Press, 2013).

8. Hegerl, G. C. et al. in Climate Change 2007: The Physical Science Basi (eds Solomon, S. et al.) Ch. 9 (IPCC, Cambridge Univ. Press, 2007).

9. Boucher, O. et al. in Climate Change 2013: The Physical Science Basis (eds Stocker, T. F. et al.) Ch. 7 (IPCC, Cambridge Univ. Press, 2013).

10. Taylor, K. E., Stouffer, R. J. \& Meehl, G. A. An overview of CMIP5 and the experiment design. Bull. Am. Meteorol. Soc. 93, 485-498 (2012).

11. Shindell, D. T. et al. Radiative forcing in the ACCMIP historical and future climate simulations. Atmos. Chem. Phys. 13, 2939-2974 (2013).

12. Andrews, T., Gregory, J., Webb, M. \& Taylor, K. Forcing, feedbacks and climate sensitivity in CMIP5 coupled atmosphere-ocean climate models. Geophys. Res. Lett. 39, L09712 (2012).

13. Forster, P. M. et al. Evaluating adjusted forcing and model spread for historical and future scenarios in the CMIP5 generation of climate models. J. Geophys. Res. 118, 1139-1150 (2013).

14. Hansen, J., Sato, M. \& Ruedy, R. Radiative forcing and climate response. J. Geophys. Res. 102, 6831-6864 (1997).

15. Forster, P. M. d. F., Blackburn, M., Glover, R. \& Shine, K. P. An examination of climate sensitivity for idealised climate change experiments in an intermediate general circulation model. Clim. Dynam. 16, 833-849 (2000).

16. Shindell, D. \& Faluvegi, G. Climate response to regional radiative forcing during the 20th century. Nature Geosci. 2, 294-300 (2009).

17. Joshi, M. et al. A comparison of climate response to different radiative forcings in three general circulation models: towards an improved metric of climate change. Clim. Dynam. 20, 843-854 (2003).

18. Stuber, N., Ponater, M. \& Sausen, R. Why radiative forcing might fail as a predictor of climate change. Clim. Dynam. 24, 497-510 (2005).

19. Boer, G. \& Yu, B. Climate sensitivity and response. Clim. Dynam. 20 415-429 (2003)

20. Shindell, D. et al. Spatial scales of climate response to inhomogeneous radiative forcing. J. Geophys. Res. 115, D19110 (2010).

21. Boucher, O. \& Reddy, M. S. Climate trade-off between black carbon and carbon dioxide emissions.. Energy Policy 36, 193-200 (2008).

22. Morice, C., Kennedy, J., Rayner, N. \& Jones, P. Quantifying uncertainties in global and regional temperature change using an ensemble of observational estimates: The HadCRUT4 data set. J. Geophys. Res. 117, D08101 (2012).

23. Cowtan, K. \& Way, R. G. Coverage bias in the HadCRUT4 temperature series and its impact on recent temperature trends. Q. J. R. Meteorol. Soc. http://dx.doi.org/10.1002/qj.2297 (2014).

24. Van Vuuren, D. P. et al. The representative concentration pathways: An overview. Climatic Change 109, 5-31 (2011).

25. Armour, K., Bitz, C. \& Roe, G. Time-varying climate sensitivity from regional feedbacks. J. Clim. 26, 4518-4534 (2013).

26. Rogelj, J., Meinshausen, M. \& Knutti, R. Global warming under old and new scenarios using IPCC climate sensitivity range estimates. Nature Clim. Change 2, 248-253 (2012)

27. Smith, S. J. \& Mizrahi, A. Near-term climate mitigation by short-lived forcers. Proc. Natl Acad. Sci. USA 110, 14202-14206 (2013).

28. Shindell, D. et al. Simultaneously mitigating near-term climate change and improving human health and food security. Science 335, 183-189 (2012).

29. Rohling, E. et al. Making sense of palaeoclimate sensitivity. Nature 491, 683-691 (2012)

30. Shindell, D. T. et al. Interactive ozone and methane chemistry in GISS-E2 historical and future climate simulations. Atmos. Chem. Phys. 13, 2653-2689 (2013).

\section{Acknowledgements}

I acknowledge the World Climate Research Programme's Working Group on Coupled Modelling and the US Department of Energy's Program for Climate Model Diagnosis and Intercomparison, and I thank the climate modelling groups from CMIP and the Atmospheric Chemistry and Climate Model Intercomparison Project (listed in Supplementary Table 1) for making available their model output. I thank G. Faluvegi and G. Milly for assistance with data analysis and US taxpayers and D. Considine for their support through NASA’s Modeling, Analysis and Prediction Program.

\section{Additional information}

Supplementary information is available in the online version of the paper. Reprints and permissions information is available online at www.nature.com/reprints.

\section{Competing financial interests}

The author declares no competing financial interests. 